\title{
Implementing alcohol screening and brief intervention in primary care: identifying barriers, proposing solutions
}

\author{
J Aaron Johnson ${ }^{*}$, J Paul Seale ${ }^{2}$ \\ From 2014 Addiction Health Services Research (AHSR) Conference \\ Boston, MA, USA. 15-17 October 2014
}

\section{Background}

Alcohol screening and brief intervention (SBI) can reduce heavy and harmful alcohol use [1-5]. The strongest evidence for SBI effectiveness is in primary care settings where meta-analyses studies show $10-30$ percent reductions in alcohol consumption at 12 months [4,5].

Over the past decade, there have been significant efforts to support the adoption and implementation of SBI in general health-care settings, including \$305 million in SBI service and training grants from the Substance Abuse and Mental Health Services Administration (SAMHSA), and approximately $\$ 17$ million per year from the National Institute on Alcohol Abuse and Alcoholism for more than 40 SBI studies. In addition, numerous individual state initiatives have focused on SBI dissemination. Nonetheless, a recent Centers for Disease Control and Prevention survey found alcohol SBI is rarely performed [6]. Only 1 in 6 adults reported they had talked with a health professional about their alcohol use in the past year [6]. The present study uses data from two SAMHSA-funded projects to identify barriers to widespread implementation of SBI and propose potential solutions.

\section{Methods}

Data are from two separate and distinct sources. Data from specialists performing SBI in an emergency department (ED) setting with over 4800 patients over 12 months are used to estimate potential revenues generated.

Family medicine and internal medicine residents in four clinics were administered questionnaires before SBI training and one year later. These data are used in reporting

\footnotetext{
* Correspondence: Aaron.Johnson@gru.edu

'Institute of Public and Preventive Health, Georgia Regents University, Augusta, GA, 30912, USA

Full list of author information is available at the end of the article
}

residents' confidence in performing SBI, level of importance placed on SBI, and residents' individual drinking behavior.

\section{Results}

Barriers to SBI implementation include low reimbursement rates and limited payers for SBI codes, restrictions on who can bill SBI codes, restrictions on same-day billing for mental health and primary care services, and minimum time requirements for billing that are much longer than time requirements for tobacco cessation. Additionally, existing Medicaid codes are not active in many states. Revenue estimates from the ED study found revenues generated would not sustain specialist-delivered SBI, with eight FTE specialists generating approximately $\$ 65,000$ per year.

While SBI training for residents results in increases in knowledge and confidence, most studies show little change in delivery of brief interventions [7-9]. Results from resident questionnaires indicate residents are more comfortable addressing patients' drug use than alcohol use. One possible contributing factor is residents' own drinking behavior. Residents' past-year binge drinking rate $(49.7 \%)$ is 20 percentage points higher than among other adults age $25-35$.

\section{Conclusions}

Based on existing literature and results from these two projects, we recommend formal recognition and credentialing of health promotion specialists who would be able to bill SBI codes. Specialists should be cross-trained to provide other billable services to make the position more sustainable. Policy changes should be enacted to address the aforementioned billing issues. Absent policy changes, technology may present an attractive alternative. High 
rates of screening are possible when screening questions are integrated into electronic health records. Computer and web-based brief interventions have shown promising results in clinical trials and could be implemented as a first step in a stepped-care SBI model, resulting in significant cost savings.

\section{Authors' details}

${ }^{1}$ Institute of Public and Preventive Health, Georgia Regents University, Augusta, GA, 30912, USA. ²Department of Family Medicine, Medical Center of Central Georgia and Mercer University School of Medicine, Macon, GA, 31206, USA.

Published: 20 February 2015

\section{References}

1. Gryczynski J, Mitchell SG, Peterson TR, Gonzales A, Moseley A, Schwartz RP: The relationship between services delivered and substance use outcomes in New Mexico's screening, brief intervention, referral and treatment (SBIRT) initiative. Drug Alcohol Depend 2011, 118:152-157.

2. McQueen J, Howe TE, Allan L, Mains D, Hardy V: Brief interventions for heavy alcohol users admitted to general hospital wards. Cochrane Database Syst Rev 2011, 8:CD005191.

3. Moyer A, Finney JW, Swearingen CE, Vergun P: Brief interventions for alcohol problems: a meta-analytic review of controlled investigations in treatment-seeking and nontreatment-seeking populations. Addiction 2002, 97:279-292.

4. Bertholet N, Daeppen J-B, Wietlisbach V, Fleming M, Burnand B: Reduction of alcohol consumption by brief alcohol intervention in primary care: Systematic review and meta-analysis. Arch Intern Med 2005, 165:986-995.

5. Kaner EF, Dickinson $\mathrm{HO}$, Beyer $\mathrm{F}$, et al: The effectiveness of brief alcohol interventions in primary care settings: A systematic review. Drug Alcohol Rev 2009, 28:301-323.

6. Centers for Disease Control and Prevention. Alcohol screening and counseling: An effective, but underused health service. CDC Vital Signs 2014.

7. Chossis I, Lane C, Gache P, Michaud PA, Pecoud A, Rollnick S, Daeppen JB: Effect of training on primary care residents' performance in brief alcohol intervention: A randomized controlled trial. Int J Gen Med 2007, 22:1144-1149.

8. Saitz R, Horton NJ, Sullivan LM, Moskowitz MA, Samet JH: Addressing alcohol problems in primary care: A cluster randomized, controlled trial of a systems intervention. The screening and intervention in primary care (SIP) study. Ann Int Med 2003, 138:372-382.

9. Seale JP, Velasquez MM, Johnson JA, et al: Skills-based residency training in alcohol screening and brief intervention: Results from the GeorgiaTexas "Improving Brief Intervention" project. Subst Abuse 2012, 33:261-271.

doi:10.1186/1940-0640-10-S1-A24

Cite this article as: Johnson and Seale: Implementing alcohol screening and brief intervention in primary care: identifying barriers, proposing solutions. Addiction Science \& Clinical Practice 2015 10(Suppl 1):A24

\section{Submit your next manuscript to BioMed Central and take full advantage of:}

- Convenient online submission

- Thorough peer review

- No space constraints or color figure charges

- Immediate publication on acceptance

- Inclusion in PubMed, CAS, Scopus and Google Scholar

- Research which is freely available for redistribution

Submit your manuscript at www.biomedcentral com/submit
Biomed Central 